\title{
Gasless Laparoscopic Anatomy and Renal Biopsy of the Kidney in the Standing Mare
}

\author{
Anatomía Laparoscópica sin Gas y Biopsia Renal de los Riñones de la Yegua de Pie
}

\author{
Mostafa M. Kassem*; Mahmoud H. El-Kammar*; Mohamed A.M. Alsafy**; \\ Samir A.A. El-Gendy"*; Ahmed Sayed-Ahmed ${ }^{* * * *}$ \& Ahmed N. EL-Khamary ${ }^{* * * * *}$
}

\begin{abstract}
KASSEM, M. M.; EL-KAMMAR, M. H.; ALSAFY, M. A. M.; EL-GENDY, S. A. A.; SAYED-AHMED, A. \& EL-KHAMARY, A. N. Gasless laparoscopic anatomy and renal biopsy of the kidney in the standing mare. Int. J. Morphol., 32(4):1234-1242, 2014.

SUMMARY: The current study aimed to provide the topography and renal biopsy of the standing mare kidneys by laparoscopy $\mathrm{w}$ ithout $\mathrm{CO}^{2}$ insufflation and to compare between the use of biopsy needle and forceps. Five clinically healthy adult nonpregnant mares weighing $250-300 \mathrm{Kg}$ and aging 7-9 years were used in the current work. The gasless laparoscopic renal biopsy appeared simple, safe, reliable, minimal invasive, timesaving and economical technique. The parallel biopsy portals provided easy and accessible biopsy procedure than dorsal or ventral portals. The biopsies taken from the lateral surface were less hemorrhagic than those taken from the caudal pole. This study recommended the laparoscopic forceps because the biopsy forceps provided satisfactory and representative specimens with minimal hemorrhage than Tru-cut needle.
\end{abstract}

KEY WORDS: Laparoscopy; Anatomy; Renal biopsy; Mare; Gasless.

\section{INTRODUCTION}

Renal biopsy is a useful diagnostic technique for evaluation and management of medical renal disease. Renal biopsy often gives valuable information in deciding prognosis and guiding therapy. Although several methods were available, percutaneous renal biopsy was the most common method of sampling renal tissue because it is minimally invasive and can be performed under local analgesia (Manoligod \& Pirani, 1985; Shetye et al., 2003). About 5 to $20 \%$ of percutaneous renal biopsy cases were yielded inadequate tissue for histopathology diagnosis (Wickre \& Golper, 1982). Relative contraindication to percutaneous renal biopsy included previous failed attempts at percutaneous biopsy, presence of a renal aneurysm, obese or uncooperative patients, coagulopathy and kidneys that are ectopic, small or solitary (Gault \& Muehrcke, 1983). In the past, the patients have undergone open renal biopsy with the associated risk for significant postoperative morbidity. With advances in endoscopic instrumentation, laparoscopic renal biopsy provided a minimally invasive alternative to open renal biopsy. By laparoscopy, the kidney was identified, biopsied and hemostasis was achieved under direct vision. Laparoscopic renal biopsy with the use of $\mathrm{CO}^{2}$ insufflation was described in horses (Fischer, 2002; Hendrickson \& Wilson, 1996; Trostle, 2000; Tabet et al., 2005). Insufflation of $\mathrm{CO}^{2}$ into the peritoneal cavity is a routine technique for abdominal exposure in laparoscopic surgery (Freeman, 1999). The insufflation was used to create pneumoperitoneum that improved the visualization and simplified the instrumental and visceral manipulation during surgery (Latimer et al., 2003). In standing laparoscopy of horse, high pressure pneumoperitoneum over $15 \mathrm{mmHg}$ produced discomfort, restlessness and even collapse in prolonged examination periods (Traub-Dargatz, 1992) and changes in physiological status during endosurgical procedures (Bailey \& Pablo, 1999) and if the patient moved extensively, damage to laparoscopic equipment and contamination of the abdomen due to loss of aseptic technique was result (Traub-Dargatz). The discomfort was produced by the elevated pressure in the peritoneal cavity can be avoided by the lack of gas insufflation. So, the aim of the current study was to provide laparoscopic renal biopsy in standing mare without $\mathrm{CO}^{2}$ insufflation, to evaluate the utility of this approach for obtaining renal samples in standing mare and to compare between the use of biopsy needle and forceps.

* Surgery Department, Faculty of Veterinary Medicine, Alexandria University, Behera, Egypt.

** Anatomy \& Embryology Department, Faculty of Veterinary Medicine, Alexandria University, Behera, Egypt.

**** Anatomy \& Embryology Department, Faculty of Veterinary Medicine, Damanhour University, Damanhour, Egypt.

****: Surgery Department, Faculty of Veterinary Medicine, Damanhour University, Damanhour, Egypt. 


\section{MATERIAL AND METHOD}

Five clinically healthy adult nonpregnant mares weighing 250-300 kilograms and aging 7-9 years were used in the current work. This study followed the guidelines for the care and use of animals and it was approved by the animal welfare and Ethics Committee of the Faculty of Veterinary Medicine, Alexandria University according the Egyptian's laws.

Topographic anatomical approach of the kidney. One cadaver mare (died due to cause not related to our study) opened from the right and left side of abdomen to determine the anatomical landmarks needed for gasless laparoscopic renal biopsy.

\section{Laparoscopic technique}

Animals. Four clinically healthy adult nonpregnant mares were used for gasless laparoscopic anatomy and renal biopsy. The day prior to the surgery, all mares were undergone a complete physical examination, a complete blood profile and a clotting profile to verify that they had not clinical abnormalities. Animal's preparation; Food but not water were withhold for 18-24 $\mathrm{h}$. Single dose of $3000 \mathrm{IU}$ tetanus antitoxin prophylaxis 10,000 IU/kg Procaine penicillin G+10mg streptomycin/kg (Combi-Kel, Kela Laboratoria, Belgium) and $1.1 \mathrm{mg} / \mathrm{kg}$ nonsteriodal anti-inflammatory flunixin meglumine (Finadyne, Intervet Shering-Plough Animal Health) were given before laparoscopic procedures. Both paralumbar fossae were clipped and aseptically prepared with a povidine-iodine antiseptic solution (Betadine, the Nile Company for pharmaceutical and chemical industries-Cairo-A.R.E.). The tail was braided and tied on the opposite side. All mares were restrained in a stock and sedated with detomidine hydrochloride (Detomo Vet 10 $\mathrm{mg} / \mathrm{ml}$-Nature Vet, PTY LTD) in a dose of $20 \mathrm{mg} / \mathrm{L}$ saline intravenous infusion (Hendrickson, 2009). Local anesthesia was achieved by direct infiltration of the laparoscopic portal sites with about $20 \mathrm{ml}$ of $2 \%$ lidocaine hydrochloride (Debocaine $2 \%$, Al-Debeiky Pharma, Egypt).

Laparoscopic equipments and instrumentation. Standard laparoscopic instruments were $300-\mathrm{W}$ xenon light source; $4.8 \mathrm{~mm}$ diameter optic light cable; 45-cm-long, $10-\mathrm{mm}$ diameter, rigid laparoscope providing a $0^{\circ}$ view; 15 -cm-long, 11-mm-diameter reusable trocar and cannula with a safety shield and Metzenbaum curved scissors 33-cm long with a 5-mm- diameter. Biopsy instruments were tru-Cut biopsy needle (Tru-cut 20/16 semi-automatic, Ghatwary Medical Supply-Egypt) and Blakesley biopsy punch $(33 \mathrm{~cm}$ and 5 $\mathrm{mm}$ diameter) (Fig.1/C-D). All equipment was purchased from Endoservice optical instruments $\mathrm{GmbH}$, Germany.
Gasless (Isobaric) laparoscopic renal biopsy techniques. Two close renal specimens were taken from the caudal or lateral aspects of kidney using Tru-cut needle and $5 \mathrm{~mm}$ laparoscopic biopsy forceps. Kidney biopsies were taken from the bilateral paralumbar fossa. The procedure started on the left side of the abdomen to avoid the cecal injury. Routine insertion of the laparoscope into the abdominal cavity was performed according to open technique (Lee \& Hendrickson, 2008). The first laparoscopic portal found in the left paralumbar fossa. Stab incision 10-12 mm was made through the skin toward the base of the tubercoxae, midway between the tubercoxae and the last rib. A cannula with blunt trocar $10 \mathrm{~mm}$ diameter, $15 \mathrm{~cm}$ long with open air valve was advanced through the subcutaneous tissues and the abdominal wall towards the opposite stifle until the penetration of the peritoneum was achieved. The trocar was replaced by the laparoscope connected to the 300 watt xenon light source and laparoscopic camera, which was used to confirm the penetration through the parietal peritoneum. No pressurized insufflation was performed. The laparoscope was directed to the upper left quadrant for observation of the anatomical landmarks needed for the renal biopsy. The same steps were performed to the right side.

Biopsy forceps. The second portal was created under direct laparoscopic guidance through a separate stab incision $5 \mathrm{~cm}$ parallel, ventral or dorsal to the laparoscope (Fig. 3A). The perirenal fascia and renal capsule were transected using a 5$\mathrm{mm}$ laparoscopic scissors in a cross pattern by rotating the scissors $90^{\circ}$ after the first cut (Fig. 4B-C), then a biopsy sample was obtained with a 5-mm Blakesley biopsy forceps introduced through the second port into the cross incision of the capsule. The obtained sample was examined to find out the presence of renal tissues.

Tru-cut needle. After the kidney was inspected, the selective area was identified. Under direct laparoscopic observation, the needle (Tru-cut 20/16 semi-automatic, Ghatwary Medical Supply-Egypt) was inserted through the abdominal wall directly above and perpendicular to the selective area. The barrel of the Tru-Cut was advanced through the renal parenchyma to obtain the specimen. The depth of the needle entry into the kidney was judged by laparoscopic vision and ruler of the needle (Fig. 3D-F). In the two biopsy techniques, the laparoscope was left in situ until it was possible to verify that hemorrhage was controlled. If the hemorrhage did not cease within 3 minutes, pressure was applied over the biopsy site using the tip of the laparoscope or biopsy forceps. Upon completion, the laparoscopic instruments were removed and the skin incision was closed with one simple interrupted stitches of non-absorbable nylon suture (2-0 Monosof USS DG nylon polyamide, United State Surgical). 


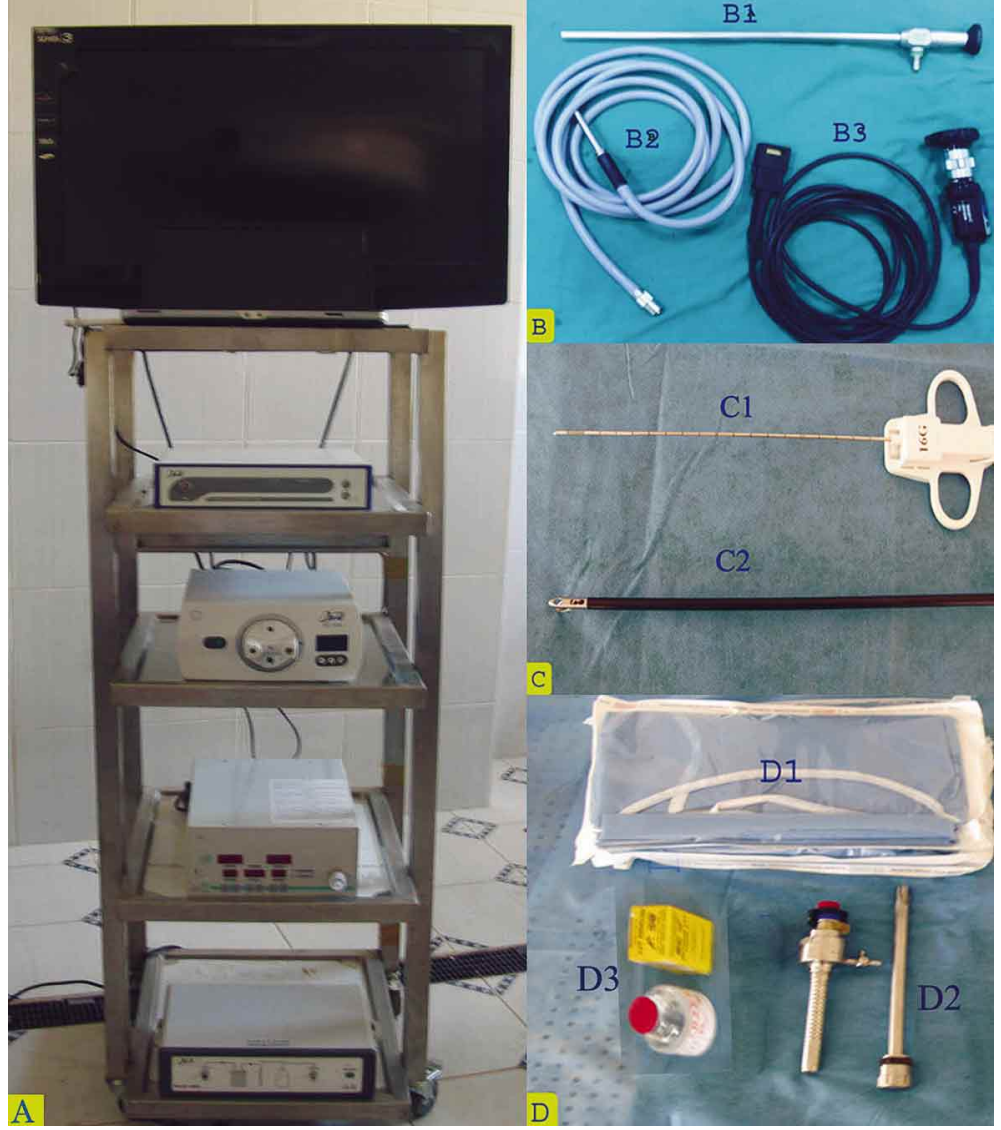

Fig. 1. Laparoscopic equipments and instrumentation. (A) Laparoscopic tower from top to bottom; T.V. monitor, camera control unit, xenon light source, insufflator, suction and irrigation machine. (B) Optical system. (B1) Zero degree laparoscope. (B2) Light cable. (B3) Video camera. (C1) tru-cut 20/16 semiautomatic biopsy needle. (C2) Blakesley punch biopsy forceps. (D1) Disposable draps. (D2) $11 \mathrm{~mm}$ reusable cannula with clip on reducer and blunt tip trocar. (D3) from left Depocaine local anesthetic drug and Detomo Vet sedative drug.

Evaluation of the two renal biopsy techniques. The two renal biopsy techniques were evaluated as regards to safety. Clinical monitoring of the animals for the three days post the procedures was measured; (respiration, heart rate, temperature, appetite, attitude, capillary refill time, the color of mucous membrane in addition of complete blood count), intensity of bleeding; severe (the blood collection was stayed in perirenal space in all extension), moderate (the blood collection was housed in part of the perirenal space) and minimal (only a trickle of blood came out the kidney), operative time (it was defined as the time from introduction to removal of laparoscope) and significance of the obtained sample.

Histological evaluation of renal samples. The renal samples obtained were fixed in $10 \%$ neutral buffered formalin. Tissue specimens were embedded in paraffin, sectioned at $5 \mu \mathrm{m}$ and stained with hematoxyline and eosin (H-E). Slides considered satisfactory, when there was a minimum of five glomeruli, tubules and vessels bypassed, allowing the realization of histological diagnosis (Tabet et al., 2005).
Postoperative management. After surgery the mares were kept in box stalls for three days to clinical monitoring. Feed was gradually reintroduced and generally not offered ad libitum until 36 to $48 \mathrm{~h}$ after surgery. All mares had a second-look laparoscopic examination 7 days after the initial gasless laparoscopic renal biopsy for evaluating evidence of inflammation, adhesion, hematoma formation and characters of healing. Skin sutures were removed 10 days postoperatively.

\section{RESULTS}

All mares had normal physical examination and laboratory data within normal reference intervals.

Topographic anatomical approach of the kidney. The left kidney was medial to the spleen and appeared from the 16th intercostal space to caudal to the $18^{\text {th }}$ rib in contact with ascending colon (Fig. 2A). The right kidney appeared from the $15^{\text {th }}$ intercostal space to caudal to the $18^{\text {th }}$ rib in contact with the base of the cecum (Fig. 2B). Important landmarks for the left kidney were the spleen, renosplenic ligament and suspensory ligament of the left ovary and for right kidney were the caudal duodenal flexure and caudate process of the liver (Fig. 2).

Basic laparoscopic technique. The standing laparoscopy in mares provided an easy access to the two kidneys. The anesthetic protocol using sedation and local analgesia was sufficient to control pain during surgical intervention in the standing mare. Open technique for insertion of the first port minimized the chances of injuring underlying structures. Surgery was performed on the left flank without any complications. Withholding food for 24 to $36 \mathrm{~h}$ with free access to water before laparoscopy was reduced the bulk in the peritoneal cavity and was improved the working space.

Gasless laparoscopic anatomy of the kidney. Gasless laparoscopic anatomy of the kidney provided sufficient and clear anatomical landmarks for gasless renal biopsy. The left kidney was easily identified by finding the dorsal edge of the spleen and the renosplenic 


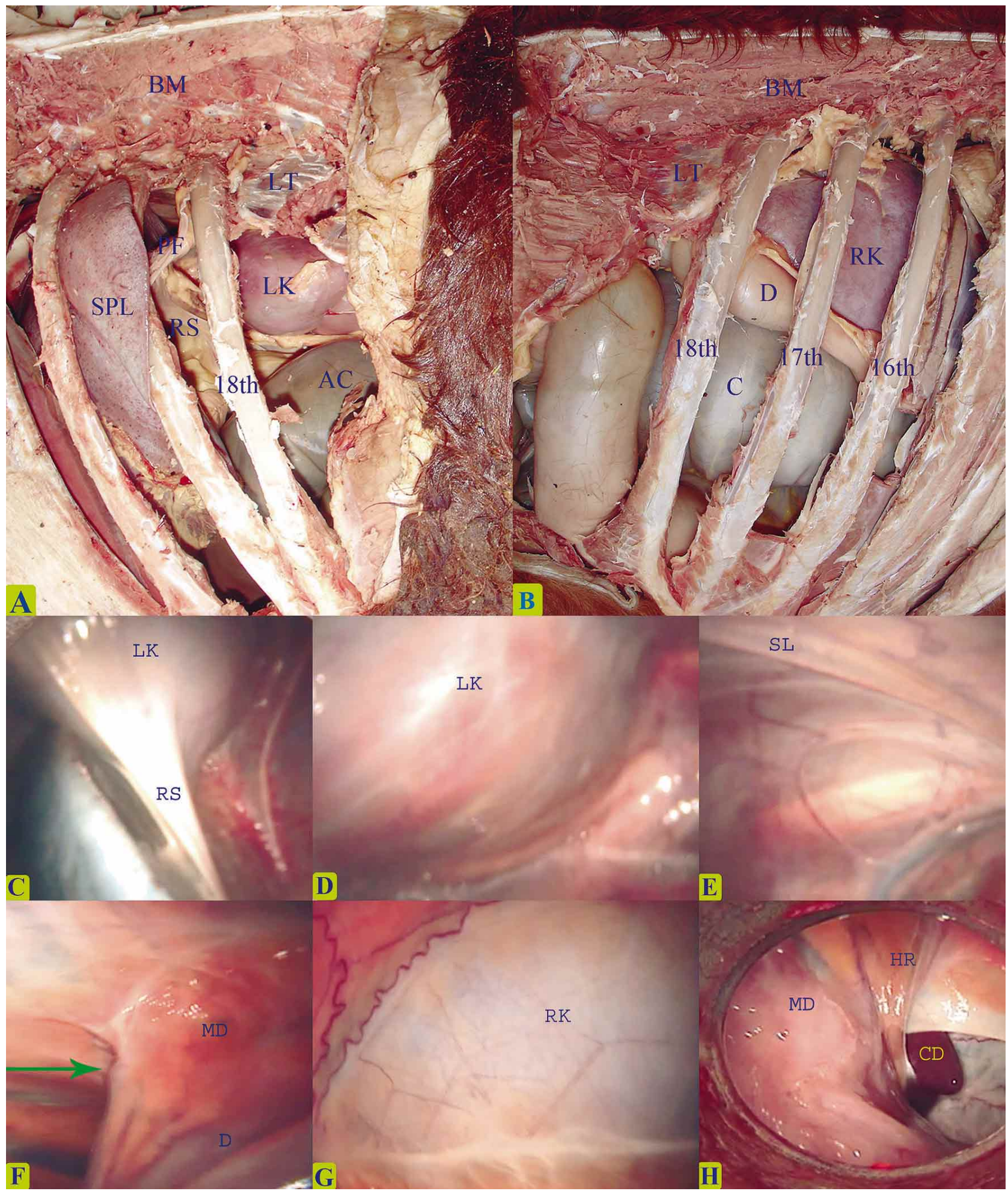

Fig. 2. Anatomical landmarks of the right and left kidneys. (A) left gross anatomical view of the abdomen of mare showed (LK) Left kidney, (LT) 1st lumbar transverse process, (BM) Back muscles, (SPL) Spleen, (PF) Perirenal fascia, (AC) Ascending colon and (RS) renosplenic ligament. (B) Right gross anatomical view of the abdomen of mare showed right (RK) kidney, (C) Cecum, (D) duodenum and 16th, 17th and 18th ribs. (C-E) laparoscopic landmarks for left kidney (LK) were showed spleen (SPL), renosplenic ligament (RS) and suspensory ligament (SL) of left ovary (OV). (F-H) Laparoscopic landmarks for right kidney (RK) were showed caudal duodenal flexure (green arrow), caudate process of the liver (CD), hepatorenal ligament (HR), duodenum (D) and mesoduodenum (MD). 


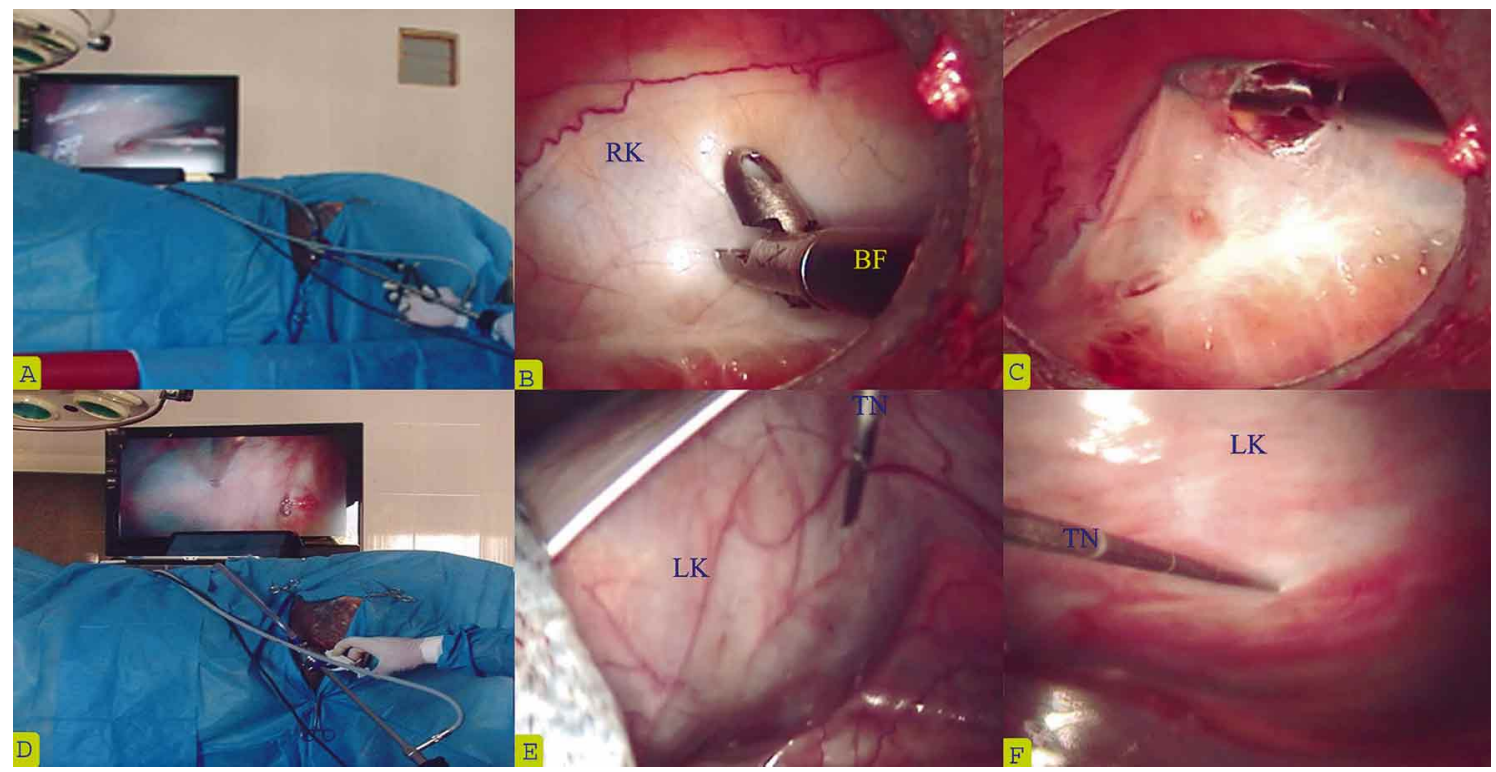

Fig. 3. Gasless laparoscopic renal biopsy. (A-C) Laparoscopic renal biopsy using Blakesly biopsy forceps. (A) Portal placement; laparoscopic port was appeared on the left side and the biopsy forceps port was appeared on the right side. $(B \& C)$ Dissection of the renal capsule in across pattern was achieved by rotating the biopsy forceps 90 degree after the first cut then a biopsy specimen was obtained. (D-F) Laparoscopic renal biopsy using Tru-cut needle. (D) Portal placement; laparoscopic port was appeared on the left side and the biopsy forceps port was appeared on the right side. (E\&F) The barrel of needle was advanced directly through the renal parenchyma to obtain renal specimen. (RK) right kidney, (BF) Blakesly biopsy forceps, (LK) left kidney, (TN) Tru-cut biopsy needle.

ligament that was identified by its shape and the presence of perirenal adipose tissue. The right kidney was easily seen than the left kidney, it was identified caudal and dorsal to the caudate process of the liver, the hepatorenal ligament and the caudal duodenal flexure. The ventral surface of the right kidney was identified easily in case of less perirenal fat (Fig.2).

Gasless laparoscopic renal biopsy. Laparoscopic access was achieved in all cases and no complications were encountered. Mares showed no signs of ataxia, distress, or discomfort during the procedure or postoperative. No changes in temperature, heart rate, respiration, appetite, defecation, urination, capillary refill time and complete blood count during the postoperative three days of evaluation. Laparoscopic renal biopsy techniques offered advantages of the direct visualization of the kidney and selection of the exact biopsy site. Puncture of unintended organs was avoided by the direct visualization of the biopsy instruments during the procedure. Fasting for 18 hours prior surgery, with free access to water, was enough to decrease the visceral volume, improve the working space and allow access for renal biopsy. Abdominal pressure increased from $-5 \mathrm{~mm} \mathrm{Hg}$ to $0 \mathrm{~mm} \mathrm{Hg}$ without any insufflation (Fig. 4).

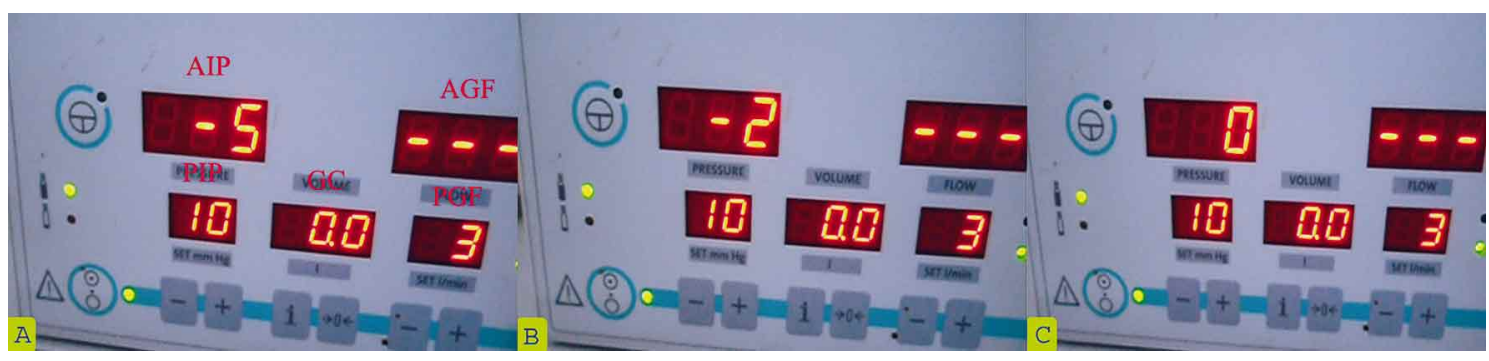

Fig. 4. The intra-abdominal pressure on electronic insufflator during gasless laparoscopic renal biopsy. Note increasing actual intra-abdominal pressure (AIP) as indication for aspiration of some room air into the abdomen with zero record for total gas consumption (GC) and actual gas flow rate (AGF). (PIP) preset intra-abdominal pressure and (PGF) preset flow rate. 


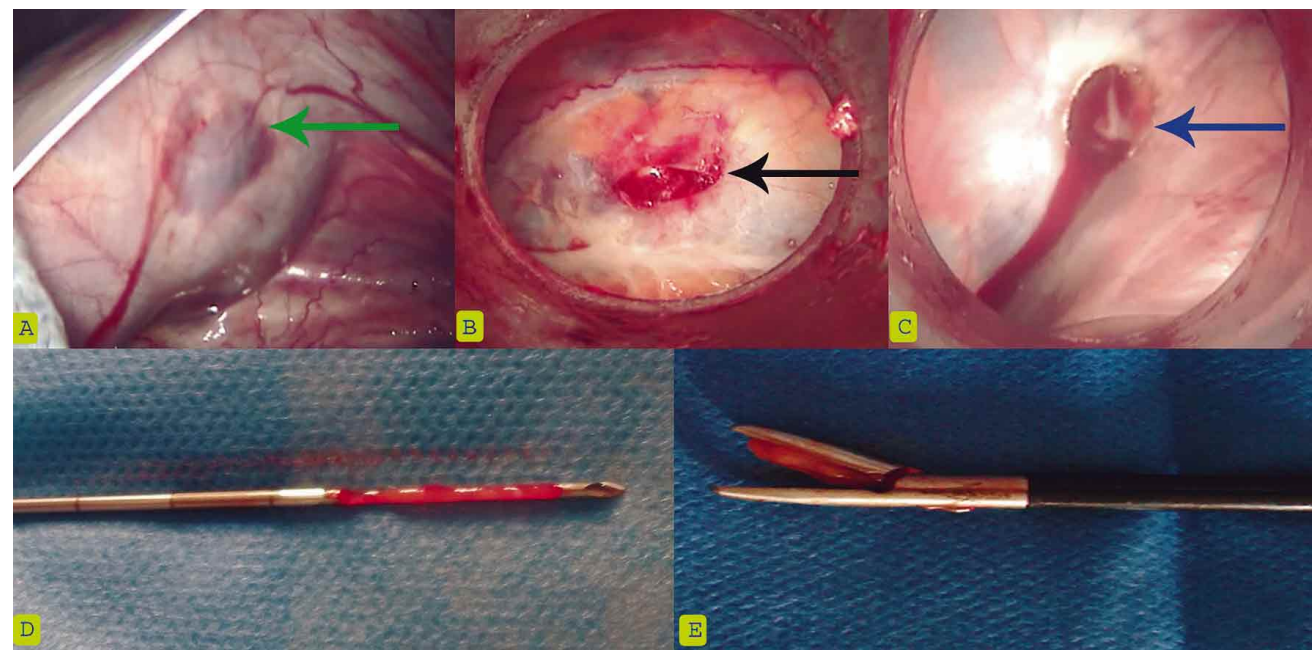

Fig. 5. Post biopsy site and biopsy specimens for gasless laparoscopic renal biopsy. (A) The appearance of perirenal hematoma (green arrow) formation after Tru-cut needle renal biopsy. (B\&C) By using biopsy forceps; the biopsy that was taken from the lateral renal surface (black arrow) was appeared less hemorrhagic than that was taken from the caudal pole (blue arrow). (D) Renal biopsy specimens collected by Tru-cut biopsy needle. (E). Blakesley biopsy forceps.

The mean biopsy times of each kidney were $5.5 \pm 0.92$ min for biopsy forceps and $3.5 \pm 0.6 \mathrm{~min}$ for Tru-cut needle. Two biopsy techniques resulted in minimal to moderate hemorrhage at the biopsy site (Fig. 5A-C). Our study was denoted the intensity of bleeding immediately after biopsy that appeared severe $0 / 8$, moderate $5 / 8(62.5 \%)$ and minimal $3 / 8(37.5 \%)$ for Tru-cut needle while in biopsy forceps appeared severe $0 / 8$, moderate $3 / 8(37.5 \%)$ and minimal $5 / 8(62.5 \%)$. Bleeding was controlled spontaneously or with application of pressure with tip of the laparoscope or biopsy forceps for $2 \mathrm{~min}$. The parallel biopsy portals provided easily and accessible biopsy procedure than the dorsal and ventral portals. Biopsies taken from the lateral renal surface were less hemorrhagic than those taken from the caudal pole by biopsy forceps (Fig. 5B-C). The specimens collected by needle were on an average $12 \mathrm{~mm}$ long, $1.5 \mathrm{~mm}$ wide and $1 \mathrm{~mm}$ thick. Biopsy forceps had an average of $6 \mathrm{~mm}$ in length, $6 \mathrm{~mm}$ width and $4 \mathrm{~mm}$ thickness (Fig. 5D-E). All samples were classified as easy to get; easily recognizable kidney surface, no complication and performed by a single surgeon. In re-laparoscopic examination; the biopsy sites were clearly visible in the kidney surface and no adhesions, infections, or gross changes were detected in any of the cases (Fig. 6C).

Histological examination of biopsy specimens. The histological examination of the specimens was acceptable in six of the eight specimens of the group where the needle used and in eight of the eight specimens in the group collected with the forceps. Tru-cut needle represented the whole renal parenchyma including cortex and medulla. In one specimen renal cortex contained three glomeruli and large blood vessel. Laparoscopic forceps represented a large area of renal cortex and small renal medulla (Fig. 6A-B).

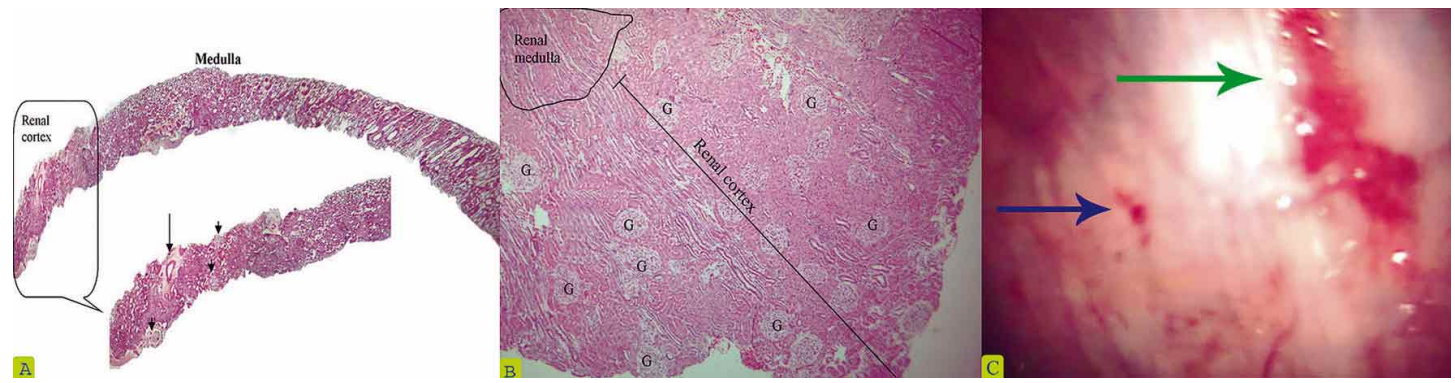

Fig. 6. Histological evaluation of renal specimens and post biopsy site during relaparoscopic examination. (A) Laparoscopic renal biopsy using Tru-cut biopsy needle was represented the whole renal parenchyma including cortex and medulla. Renal cortex was contained three glomeruli (short arrows) and large blood vessel (long arrow), nearby all medulla was represented in this biopsy. H\&E (X160). (B) Laparoscopic renal biopsy using biopsy forceps was represented large area of renal cortex contained numerous glomerlui $(\mathrm{G})$, while small outer renal medulla was represented. H\&E (X160). (C) The appearance of biopsy sites 7 days postoperative during relaparoscopic examination for biopsy forceps (green arrow) and for Tru-cut needle (blue arrow). 


\section{DISCUSSION}

In the present anatomical investigation the left kidney was medial to the spleen and appeared from $16^{\text {th }}$ intercostal space to the $18^{\text {th }}$ rib in contact with ascending colon. The right kidney appeared from the $15^{\text {th }}$ intercostal space to the $18^{\text {th }}$ rib in contact with the base of the cecum. The important landmarks for the left kidney were the spleen, renosplenic ligament and suspensory ligament of the left ovary and for the right kidney were the caudal duodenal flexure and caudate process of the liver. Gasless laparoscopic anatomy of the kidney provided sufficient and clear anatomical landmarks for gasless renal biopsy (Galuppo et al., 1995; Galuppo, 2002).

The gasless approach is feasible in the standing mare because the retroperitoneal location of the kidneys in lumber region, the suspension of the kidneys by the posterior portion of the rib cage and the renal ligaments and the aspiration of some room air provides a space between the kidneys and other organs and allow easily lateral approach to the kidneys. So biopsy could be done without the usual $\mathrm{CO}^{2}$ insufflation to create more space (Lillich et al., 2006; Budras et al., 2009; Chiesa et al., 2009).

The present study suggested the using of gasless laparoscopic renal biopsy technique as a simple, reliable (100\% success), safe, timesaving and cost-effective technique in sedated standing mare. Gasless laparoscopy reduced the operative time and cost. No pneumoperitoneum was created to improve imagining and working space, because it was already found, no gas seal was necessary to keep the intraabdominal pressure and no technical support was needed to control $\mathrm{CO}^{2}$ flow throughout the procedure. The cost of $\mathrm{CO}^{2}$ insufflation and the associated equipment was canceled. The isobaric procedure was performed by a single surgeon. Laparoscopic renal biopsy performed in horses with the use of $\mathrm{CO}^{2}$ (Fischer; Hendrickson \& Wilson; Trostle). This needed time of execution and average $\mathrm{CO}^{2}$ consumption for laparoscopic renal biopsy using Tru-cut needle was 20 minutes and 28.9 liter and 35 minutes and 35.9 liter for laparoscopic renal biopsy using forceps (Tabet et al.). Fasting for 18 hours prior surgery, with free access to water, was enough to decrease the visceral volume, improve the working space and allow access for renal biopsy. The horse was fasted for $18-24 \mathrm{~h}$ for laparoscopic renal biopsy to allow the intestine to be empty, improve the imagining (Fischer). The biopsy forceps was inserted into the abdomen through a separate stab incision 5$10 \mathrm{~cm}$ ventral or dorsal to the laparoscope (Fischer). While Tabet et al. recorded that it was created a second portal in the intercostals space under laparoscopic guidance. The biopsies were taken from the caudal pole in the cortical region to avoid the medullary blood vessels. These considerations were not in consequence with our findings. Firstly, the parallel biopsy portal provided easily and accessible biopsy procedure than dorsal or ventral portal. Because this orientation is mimic to an operating endoscope with a channel and is comfortable for surgeon in instrumental handling. Secondly, the biopsies were taken from the lateral surface were less hemorrhagic than those taken from the caudal pole. The renal arteries and veins entered the kidney at the hilus; however large accessory vessels entered the caudal part of the kidney, making it is important to avoid the caudal pole during biopsy (BarrattBoyes et al., 1991).

Our findings proved that the laparoscopic renal biopsy offered advantages of the direct imagining of the kidney and selecting the exact biopsy site. Puncture of unintended organs was avoided by the direct visualization of the biopsy instruments during the procedure. Adequate renal tissues were obtained in all cases. Recovery and convalescence were short for all cases. The lack of discomfort and the rapid recovery after surgery was attributed to the lack of gas insufflation throughout this study. The pneumoperitoneum with $\mathrm{CO}^{2}$ during standing laparoscopy in healthy horses did not cause adverse alterations in cardiopulmonary, hematology or plasma chemistry variables, but induced a mild inflammatory response within the peritoneal cavity through formation of carbonic acid on visceral surface (Latimer et al.). Moreover, the exceeding intra-abdominal pressure than $15 \mathrm{mmHg}$ may lead to profound changes in physiological status during endosurgical procedures (Bailey \& Pablo).

The laparoscopic renal biopsy was safe and effective alternative to open renal biopsy for patient in whom percutaneous biopsy was not feasible (Shetye et al.). The laparoscopic biopsy offered the ability to the direct visualization of the pathologic condition of the horse (Fischer). Excellent-quality renal biopsy specimens with large numbers of glomeruli can be obtained during laparoscopy versus ultrasound guidance (Rawlings et al., 2003). The learning curve for the ultrasound-guided procedure was steeper than that for laparoscopic biopsy (Cole et al., 2002). Some patients had absolute or relative contraindications for ultrasonographically guided percutaneous kidney biopsy, relative in patients with bleeding diatheses, extreme obesity, solitary kidney, previous failed attempts at percutaneous kidney biopsy and poorly visualized kidneys on ultrasonography (Stiles et al., 2000). Inability to co-operate for the procedure is an absolute. In re-laparoscopic examination; the biopsy sites were clearly visible in the kidney surface and no adhesions, infections or gross changes were detected in any of the cases. The using of ligating clips, intracorporeal sutures or application of electrocautery if the 
bleeding persisted or related to a vessel laceration and using a single extra dose of non-steroidal anti-inflammatory drugs or an analgesic for some horses were mildly uncomfortable following laparoscopy (Fischer; Hendrickson \& Wilson; Trostle).

Based on the results of this study, it could be recommended to use the laparoscopic biopsy forceps, however, did not rule out the possibility of using the needle because the biopsy forceps provided enough and representative specimens with minimal hemorrhage than Trucut needle that was faster technique. The reason for improving the quality of the specimens obtained with biopsy forceps was the possibility of the direct vision of the kidney capsule after dissection and dilatation of the perirenal fat and fascia; so, this provided an accurate idea of the depth of the penetration of the forceps to reach the renal parenchyma (Chiesa et al.). This was not possible with the needle biopsy because the distance between the fascia and kidney parenchyma was not clear without perirenal dissection. The biopsy forceps caused significantly less hemorrhage than Tru-cut needle due to the shape of the biopsy forceps so, the specimens was obtained from the outer portion of the kidney that reduced the chance of the penetration of a large vessel (Tabet et al.; Vasanjee et al., 2006).

Renal biopsy in horses has low morbidity and results in a morphological histopathologic diagnosis in $94 \%$ of cases. However, this procedure might result in serious complications and should only be used when information obtained (Tyner et al., 2011). It should be noted that the mares used in this study were normal and small quite sized. Body size and diseased kidney are a factor that needs to be considered as a variable that may increase the possibility of intraoperative renal biopsy complication.

\section{CONCLUSION}

Gasless approach is possible in the sedated standing mare for topographic renal anatomy and renal biopsy. Gasless laparoscopic renal biopsy was a simple, safe, reliable (100\% success), minimal invasive alternative to open renal biopsy, timesaving and economic technique with preference for the laparoscopic forceps use.

KASSEM, M. M.; EL-KAMMAR, M. H.; ALSAFY, M. A. M.; EL-GENDY, S. A. A.; SAYED-AHMED, A. \& EL-KHAMARY, A. N. Anatomía laparoscópica sin gas y biopsia renal de los riñones de la yegua de pie. Int. J. Morphol., 32(4):1234-1242, 2014.

RESUMEN: El presente estudio tuvo como objetivo proporcionar la topografía y la biopsia renal de los riñones en la yegua de pie, por laparoscopía sin insuflación de $\mathrm{CO}^{2}$, y comparar entre el uso de la biopsia con aguja y pinzas. Fueron utilizadas en este studio cinco yeguas adultas no gestantes clínicamente sanas con un peso de 250-300 Kg y edad de 7-9 años. La biopsia renal laparoscópica sin gas es un método seguro, confiable y mínimamente invasivo, económico y permite además ahorrar tiempo. Los portales de biopsia paralelas permiten un procedimiento de biopsia de fácil acceso. Las biopsias tomadas de la superficie lateral fueron menos hemorrágicas que aquellas obtenidas desde el polo caudal. Este estudio recomienda las pinzas laparoscópicas debido a que, a diferencia de la aguja Trucut, demostraron ser satisfactorias con una hemorragia mínima.

PALABRAS CLAVE: Laparoscopía; Anatomá; Biopsia renal; Yegua; Sin gas.

\section{REFERENCES}

Bailey, J. E. \& Pablo, L. S. Anesthetic and physiologic considerations for veterinary endo-surgery. In: Freeman, L. (Ed.). Veterinary endosurgery. St. Louis, Mosby, 1999. pp.2443.

Barratt-Boyes, S. M.; Spensley, M. S. \& Nyland, T. G. \& Olander, H. J. Ultrasound localization and guidance for renal biopsy in the horse. Vet. Radiol., 32(3):121-6, 1991.

Budras, K. D.; Sack, W. O. \& Röck, S. Lymphatics, Adrenal glands and Urinary organs. In: Budras, K. D.; Sack, W. O. \& Röck, S. (Eds.). Anatomy of the horse, 5th ed. Hannover, Schlutersche, 2008. pp.78-9.
Chiesa, O. A.; von Bredow, J.; Li, H. \& Smith, M. Isobaric (gasless) laparoscopic liver and kidney biopsy in standing steers. Can. J. Vet. Res., 73(1):42-8, 2009.

Cole, T. L.; Center, S. A.; Flood, S. N.; Rowland, P. H.; Valentine, B. A.; Warner, K. L. \& Erb, H. N. Diagnostic comparison of needle and wedge biopsy specimens of the liver in dogs and cats. J. Am. Vet. Med. Assoc., 220(10):1483-90, 2002.

Fischer, A. T. Laparoscopic biopsy techniques. In: Fisher, A. T. (Ed.). Equine Diagnostic \& Surgical Laparoscopy. Philadelphia, Saunders, 2002. pp.143-7. 
Freeman, L. G. Operating room set up, equipment, and instrumentation. In: Freeman, L. G. (Ed.). Veterinary endosurgery. St. Louis, Mosby, 1999. pp.3-23.

Galuppo, L. D.; Snyder, J. R. \& Pascoe, J. R. Laparoscopic anatomy of the equine abdomen. Am. J. Vet. Res., 56(4):518-31, 1995.

Galuppo, L. D. Laparoscopic anatomy. In: Fischer, A. T. (Ed.). Equine Diagnostic \& Surgical Laparoscopy. Philadelphia, Saunders, 2002. pp.7-27.

Gault, M. H. \& Muehrcke, R. C. Renal biopsy: current view and controversies. Nephron, 34:1-34, 1983.

Hendrickson, D. A. \& Wilson, D. G. Instrumentation and techniques for laparoscopic and thoracoscopic surgery in the horse. Vet. Clin. North Am. Equine Pract., 12(2):235-59, 1996.

Hendrickson, D. A. Complications of laparoscopic surgery. Vet. Clin. North Am. Equine Pract., 24(3):557-71, 2009.

Latimer, F. G.; Eades, S. C.; Pettifer, G.; Tetens, J.; Hosgood, G. \& Moore, R. M. Cardiopulmonary, blood and peritoneal fluid alterations associated with abdominal insufflation of carbon dioxide in standing horses. Equine Vet. J., 35(3):283-90, 2003.

Lee, M. \& Hendrickson, D. A. A review of equine standing laparoscopic ovariectomy. J. Equine Vet. Sci., 28(2):105-11, 2008.

Lillich, J. D.; Fischer, A. T. \& DeBowes, R. M. Kidneys, ureters and bladder. In: Auer, J. \& Stick, J. (Eds.). Equine surgery. 3rd ed. Philadelphia, Saunders, 2006. pp.870-87.

Manoligod, J. R. \& Pirani, C. L. Renal biopsy in 1985. Semin. Nephrol., 5(4):237-9, 1985.

Rawlings, C. A.; Diamond, H.; Howerth, E. W.; Neuwirth, L. \& Canalis, C. Diagnostic quality of percutaneous kidney biopsy specimens obtained with laparoscopy versus ultrasound guidance in dogs. J. Am. Vet. Med. Assoc., 223(3):317-21, 2003.

Shetye, K. R.; Kavoussi, L. R.; Ramakumar, S.; Fugita, O. E. \& Jarrett, T. W. Laparoscopic renal biopsy: a 9-year experience. BJU Int., 91(9):817-20, 2003.

Stiles, K. P.; Yuan, C. M.; Chung, E. M.; Lyon, R. D.; Lane, J. D. \& Abbott, K. C. Renal biopsy in high-risk patients with medical diseases of the kidney. Am. J. Kidney Dis., 36:419-33, 2000.

Tabet, A. F.; Silva, L. C. L. C.; Shinhorini, I. L. \& De Zoppa, A. L. V. Comparison of two laparoscopic guided renal biopsy techniques in horses. Braz. J. Vet. Res. Anim. Sci., 42(2):1506, 2005.

Traub-Dargatz, J. Laparoscopy, endoscopy and surgical biopsy in large animals. In: Anderson, N. V. (Ed.). Veterinary Gastroenterology. 2nd ed. Malvern, Lea \& Febiger, 1992, pp.61-9.
Trostle, S. Gastrointestinal endoscopic surgery. Vet. Clin. North Am. Equine Pract., 16(2):329-41, 2000.

Tyner, G. A.; Nolen-Walston, R. D.; Hall, T.; Palmero, J. P.; Couëtil, L.; Javsicas, L.; Stack, A.; Schott, H.; Johnson, A.; Hardefeldt, L.; Gruntman, A.; Sommardahl, C.; Menzies-Gow, N.; dePedro, P.; Norman, T.; Fennell; L. C.; Axon, J. E.; Lindborg, S.; Aceto, H.; Boston, R. \& Engiles, J. A multicenter retrospective study of 151 renal biopsies in horses. J. Vet. Intern. Med., 25(3):5329, 2011 .

Vasanjee, S. C.; Bubenik, L. J.; Hosgood, G. \& Bauer, R. Evaluation of hemorrhage, sample size, and collateral damage for five hepatic biopsy methods in dogs. Vet. Surg., 35(1):86-93, 2006.

Wickre, C. G. \& Golper, T. A. Complications of percutaneous needle biopsy of the kidney. Am. J. Nephrol., 2(4):173-8, 1982.

\author{
Correspondence to: \\ Mohamed Alsafy \\ Department of Anatomy \& Embryology \\ Faculty of Veterinary Medicine \\ Alexandria University \\ Edfina, Behera \\ Post Box 22785 \\ EGYPT
}

Email: Safy73@yahoo.com

Received: 15-04-2014

Accepted: 12-08-2014 